\title{
Developing a Scenario for Widespread Use: Best Practices, Lessons Learned
}

\author{
Sue Perry, ${ }^{\text {a) }}$ Lucile Jones, ${ }^{\text {a) }}$ M.EERI, and Dale Cox ${ }^{\text {b) }}$
}

The ShakeOut Scenario is probably the most widely known and used earthquake scenario created to date. Much of the credit for its widespread dissemination and application lies with scenario development criteria that focused on the needs and involvement of end users and with a suite of products that tailored communication of the results to varied end users, who ranged from emergency managers to the general public, from corporations to grassroots organizations. Products were most effective when they were highly visual, when they emphasized the findings of social scientists, and when they communicated the experience of living through the earthquake. This paper summarizes the development criteria and the products that made the ShakeOut Scenario so widely known and used, and it provides some suggestions for future improvements. [DOI: 10.1193/1.3574445]

\section{INTRODUCTION}

The ShakeOut Scenario has been used in preparedness events over several years. It was the foundation for the 2008 Great Southern California ShakeOut (which included about 5.4 million public participants and over 5,300 emergency responders), was again used by numerous participants in the 2009 statewide ShakeOut, the 2010 Federal Emergency Management Agency's Catastrophic Plan for Southern California, and the 2012 Goden Guardian statewide emergency response drill.

The ShakeOut Scenario is the first public product of a new project at the United States Geological Survey (USGS), the Multi-Hazards Demonstration Project, which was initiated in the aftermath of Hurricane Katrina to improve resiliency to natural hazards through the application of science to community decision making and emergency response. The MultiHazards Demonstration Project for Southern California (MHDP, Jones et al. 2007) began with a purview of Southern California and five years commitment from the USGS to demonstrate the effectiveness of its approach. During MHDP's formulation, MHDP organized focus groups consisting of potential end users - emergency response professionals, public officials, and resource managers - and found a strong need and interest in scenarios that would increase preparation for catastrophic natural disasters.

Work on the ShakeOut Scenario began with study of many previous earthquake scenarios, including those in California (Davis et al. 1982, Steinbrugge et al. 1986) and elsewhere (EERI 2005). Planning was particularly influenced by the scenario development guidelines of Preuss and Godfrey (2006), which MHDP sought to extend in several ways, notably:

- In the degree to which social science research was incorporated in the scenario

\footnotetext{
a) U.S. Geological Survey, Pasadena, CA

b) U.S. Geological Survey, Sacramento, CA
} 
- By involving potential end users early and as part of the development process

- By creating varied and innovative products and partnerships to communicate the results and increase community readiness for a "Big One"

MHDP equates scenario use with scenario success, and thus considers the ShakeOut Scenario to be an exceedingly successful effort. Here we summarize the choices and efforts that contributed most directly to the widespread use of this scenario, based on our observations and interactions. Because many of these choices are applicable to other scenarios or preparedness efforts, we also offer suggestions for future improvements.

\section{KEY SCENARIO DEVELOPMENT CRITERIA}

Several criteria proved critical in making the ShakeOut Scenario the foundation of large public and emergency response drills, and in compelling community attention to the completed study. We now consider these criteria as best practices in development of future MHDP scenarios. Summarized here are the criteria, relevant assumptions, outcomes, and lessons learned.

I. The event must be plausible, yet catastrophic. In Southern California there has been widespread concern that a major earthquake could be the region's version of Hurricane Katrina. Furthermore, the emergency planning community rehearses regularly for more commonplace disasters, so there seemed no "value added" in providing a scenario for a Northridge-sized earthquake. However, the bigger the earthquake, the greater the number of people who dismiss it as being too rare or improbable. To balance these needs:

- This scenario's earth scientists were tasked with designing the largest plausible event. Some earth scientists continue to debate the choice of fault and rupture parameters; a few potential participants declined to participate because they felt such large earthquakes were too rare. However, the great majority of our end users felt otherwise; they were cognizant of the risk posed by the southern San Andreas Fault and readily grasped that a scenario is a planning tool, not an earthquake forecast or prediction.

- We made the assumption that preparing for one major earthquake gets the community more ready for others that may occur instead, and this assumption proved persuasive to end users who were concerned that the ShakeOut earthquake might never actually occur.

- One limitation of any scenario is the fact that a single event will spare some constituents who must also prepare for disasters. To counter this, we reminded people that the ShakeOut Scenario is not the only earthquake that menaces Southern California, and emphasized the many ways that communities would be affected even if their initial damages were light.

II. The scenario should contribute to scientific understanding, as well as to community readiness. Many scenarios are "gray literature" products; however, as evidenced by this volume, scenario science can also merit peer-reviewed publication. Moreover, project developers approached the scenario as a venue for building on well-established research, by identifying needed new research directions, and where feasible, taking exploratory steps in those directions. Two examples include the ground motion simulations of the Southern 
California Earthquake Center and the analyses of economic recovery and resilience (Graves et al. 2011, Wein et al. 2011). By adopting this criterion, we found that:

- A scenario that accommodates leading edge research and is suitable for peerreviewed publication attracts scientists who might not otherwise allocate the time to work on a scenario.

- In the words of one end user, the "scientific pedigree" of the ShakeOut Scenario project compelled attention among potential end users and increased buy-in at their organizations.

- On the other hand, taking new research directions further compounds the challenge of producing results that are credible and widely accepted, a challenge already heightened by conducting multidisciplinary study of a what if earthquake.

III. Social science research in the scenario should be as extensive as earth science and engineering. Typically, the enormity of a disaster (whether real or scenario) is conveyed with statistics about its casualties and financial losses, but most of the scenario research is in physical science and engineering. For the ShakeOut Scenario, extensive research from disaster sociologists, economists, and decision scientists (Goltz and Mileti 2011, Wein et al. 2011) fleshed out the picture of the disaster after the shaking ceased, during the periods of emergency response and initial recovery. By increasing the amount of social science research:

- $\quad$ Planners and policy makers had more information they saw as being specific and pertinent to their decision making.

- It was easier to educate and convince potential users regarding how a major earthquake would affect them and why they should prepare for it.

- Again and again, it was a social science result that was cited as the reason for taking action to increase preparedness.

IV. The standard scientific strategy of completing a study then handing it off to prospective users is not the most effective way to apply this science. It was anticipated that users would need guidance and help in making use of the scenario's results. As a result of this:

- $\quad$ Peer-reviewed, scientific publication of the scenario was a final, not initial, step in its use. Initial release of the study was a USGS/California Geological Survey Open File Report (Jones et al. 2008), a publication venue for works in progress.

- This initial release date was set by those planning the Golden Guardian 2008 statewide emergency response exercises; it opened a six-month period of public review and comment on the scenario.

- Significant resources were devoted to creating a large number of interim products in diverse media (discussed below) to communicate the earthquake and its impacts in ways that would be comprehensible and helpful to users with varied or no expertise in science or engineering.

- The scenario sought to identify potential actions referred to as low-hanging fruit, that is, relatively small changes or actions by organizations or individuals that could significantly improve the outcome when a major earthquake occurs.

- Every step that diverged from the more standard strategy (of publishing a completed study and handing it to potential users) created noteworthy, recurring 
headaches in maintaining consistency among products and results, but by taking those steps we increased the number of people who understood our results and how to apply them to the Golden Guardian drills and the public preparedness events.

$\mathrm{V}$. It is important to maintain an aggressive schedule with rigid deadlines. Emergency responders assign their exercise topics years in advance and adhere to a tight and fast-paced schedule when planning exercises. In order to have the ShakeOut Scenario used by exercise planners, project scientists had to commit to deadlines and meet them regardless of research delays or revelations along the way. From this criterion we learned that:

- Aggressive scheduling limits iteration, yet a scenario's development is not truly linear, and iteration is especially valuable in cases where there are interdependencies among components (e.g., Porter and Sherrill 2011).

- Seemingly trivial delays early in the project had a domino effect that put considerable stress on the completion of the final stages.

- Meeting deadlines while enabling iteration and buffering later research segments from earlier project delays remain thorny issues. MHDP continues to grapple with both. In both the ShakeOut Scenario and the 2010 winter storm scenario (ARkStorm, Cox et al. 2009), successful project management has depended upon the commitment and peer respect of the coordinators heading each research group, and on continual communication among the coordinators.

\section{END USER PARTICIPATION IN SCENARIO DEVELOPMENT}

As the ShakeOut Scenario evolved, the stakeholders' focus groups expanded from emergency response professionals, public officials, and resource managers to include members of business, lifeline services, and community organizations. Initially, these potential end users of the scenario were invited to participate in scenario development because their expertise was needed regarding damages, impacts, or recovery. MHDP quickly discovered that involving potential end users in the development of the scenario provided several additional benefits. In particular, the end users:

- Sometimes revealed (and shared) hitherto unknown datasets, perspective, and contacts of value to the scenario or the ensuing preparedness events

- $\quad$ Provided extensive and specific feedback when presented with a work-in-progress rather than a fait accompli. This helped to improve the scenario in details, and also enabled the scenario to better address controversial and "hot button" topics. Some end users continued to disagree with the scenario conclusions. Nonetheless, participating in the process and seeing how conclusions were reached usually made them more amenable to accepting the validity of those conclusions.

- Felt ownership over the material and continued to think about and make use of the scenario and its partnership-building process long after the ShakeOut concluded. This process is still continuing and creates optimism that it could have long-term, positive impact on earthquake readiness in Southern California.

Collaborating with end users is another area requiring iteration at every stage of the process. Many of the end users work in large, complicated organizations with limited internal communication. Thus it has proved a considerable challenge to identify and engage the 
persons most suitable to participate in different aspects of scenario development and dissemination. Moreover, some organizations have made significant investments in earthquake mitigation, and are sensitive to wording regarding the effectiveness of that mitigation. In some cases it took iteration to present results that satisfied both end users and scenario developers.

\section{PRODUCTS AND AUDIENCES}

The ShakeOut Scenario reached a broad and diverse audience, with widely varying needs for information and detail. No single product could adequately serve all needs. Several products proved particularly important in communicating the scenario and we will create similar products for future MHDP scenarios. Although the targeted audiences were generally nontechnical, the products for the general public also helped project scientists understand the work of colleagues in distant disciplines. Below, we describe these products, their uses, and in some cases, how we might amend the product to improve future dissemination. Each of these products was essential to some segment of the scenario's users. The products are listed from most to least widely used.

"The ShakeOut Earthquake Scenario: A Story that Southern Californians Are Writing" (Perry et al. 2008, Figure 1a). This narrative has been the product that most people have used to learn about and understand the ShakeOut Scenario. Decision makers at all levels have cited this document as the reason they participated in the ShakeOut or improved earthquake readiness plans. The 16-page summary booklet has many pictures, and the layout suggests a movie unfolding. Its evolution taught us the value of unconventional approaches. It started as a more conventional scientific summary with experiential excerpts to provide a "you are there" flavor. Co-author Cox transformed the document's impact by reversing the proportions of scientific and experiential writing. The resulting piece captured the experience of being in Southern California during the ShakeOut earthquake and its aftermath. Because 16 pages cannot include all important details of a large study, in future scenarios we anticipate creating additional "stories" for specialized user situations.

MHDP partnered with designers and artists from the Art Center College of Design to create "Preparedness Now," an animated movie (Figure 1b) made by film director and motion graphics designer Theo Alexopoulos. For those who found reading the 16-page narrative tedious, this movie provided an even shorter ( 4.5 minutes) and even more visceral impression of the ShakeOut Scenario. The movie held the attention of those who otherwise found earthquakes and preparedness boring and gave the project exposure on YouTube. Of all our products, this was the one that consistently held the attention of college-aged and younger audiences.

An animation of velocity of ground motion (Figure 1a; Graves et al. 2011) was initially developed in collaboration among earth and computer scientists at the Southern California Earthquake Center and the San Diego Supercomputer Center to interrogate details of velocity modeling results. However the movie had more use outside these fields. This animation became the visual centerpiece of many months of presentations about the scenario and the subsequent ShakeOut. The movie, which shows wave velocity in shifting color patterns over time, has mesmerized audiences and has proved to be a highly effective tool in holding audience attention while making key points about major earthquakes generally and 
(a)
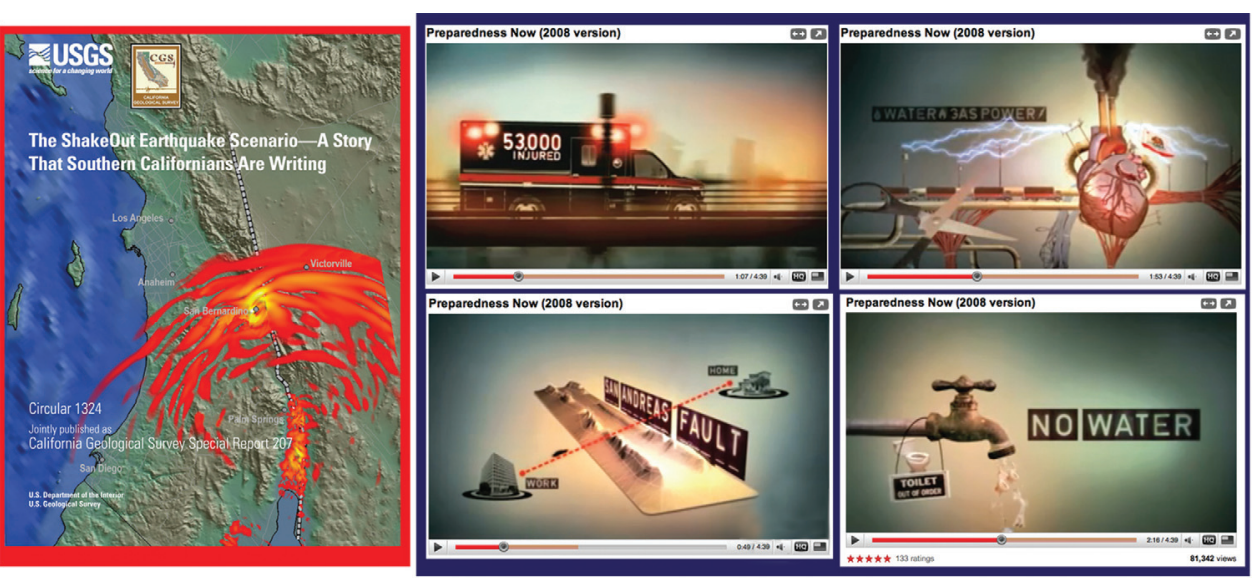

(b)

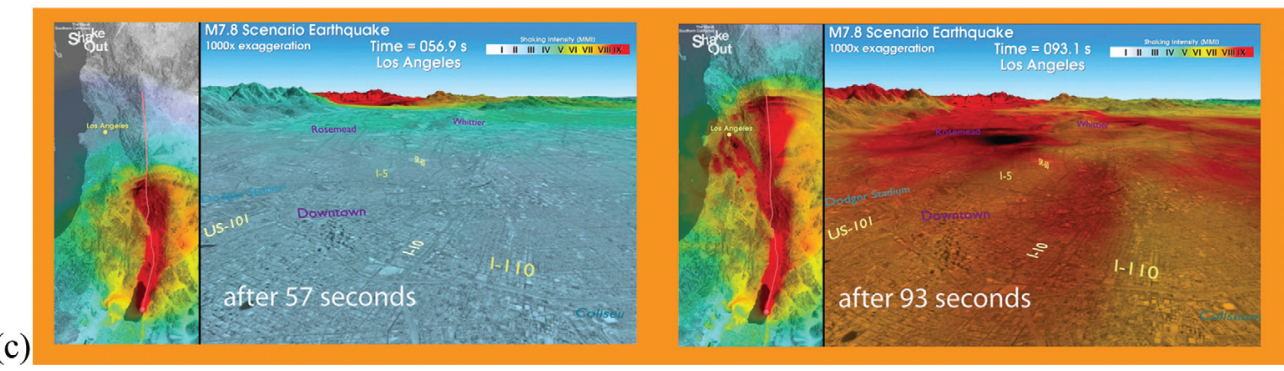

Figure 1. ShakeOut Scenario products that attracted a wide audience. (a) Cover of the 16 page narrative "story" of the earthquake. The image is a frame from the widely viewed scientific animation of peak velocity of ground motion; (b) four frames from the "Preparedness Now" animated movie, needing few words to communicate: a statistic about number of injured persons, the concept that the earthquake would sever lifelines, the problems of commuters who live and work on opposite sides of the fault rupture, and the lack of water in the quake's aftermath; (c) scientific visualization of peak intensity of ground motion, here from a vantage point looking east over downtown Los Angeles, 57 seconds (left) and 93 seconds (right) after fault rupture begins.

the ShakeOut earthquake particularly; it has been an excellent teaching aid regarding the length of fault ruptures, duration of strong shaking, and reverberation in sedimentary basins. This is a frequently downloaded animation and as a download, would have benefitted from an optional voiceover narration to guide non-geophysicists in understanding what they were seeing.

Equally attention-holding animations (Figure 1c; Aagaard 2008) showed the peak intensity of ground shaking as the earthquake waves moved through 16 distinct locations throughout Southern California. The 16 movies helped viewers to personalize the regional event to their neighborhoods, and also helped convey essential concepts of seismic wave propagation and periodicity. After seeing these animations, viewers were better able to understand how major earthquakes produce widespread, severely damaging shaking, spatial 


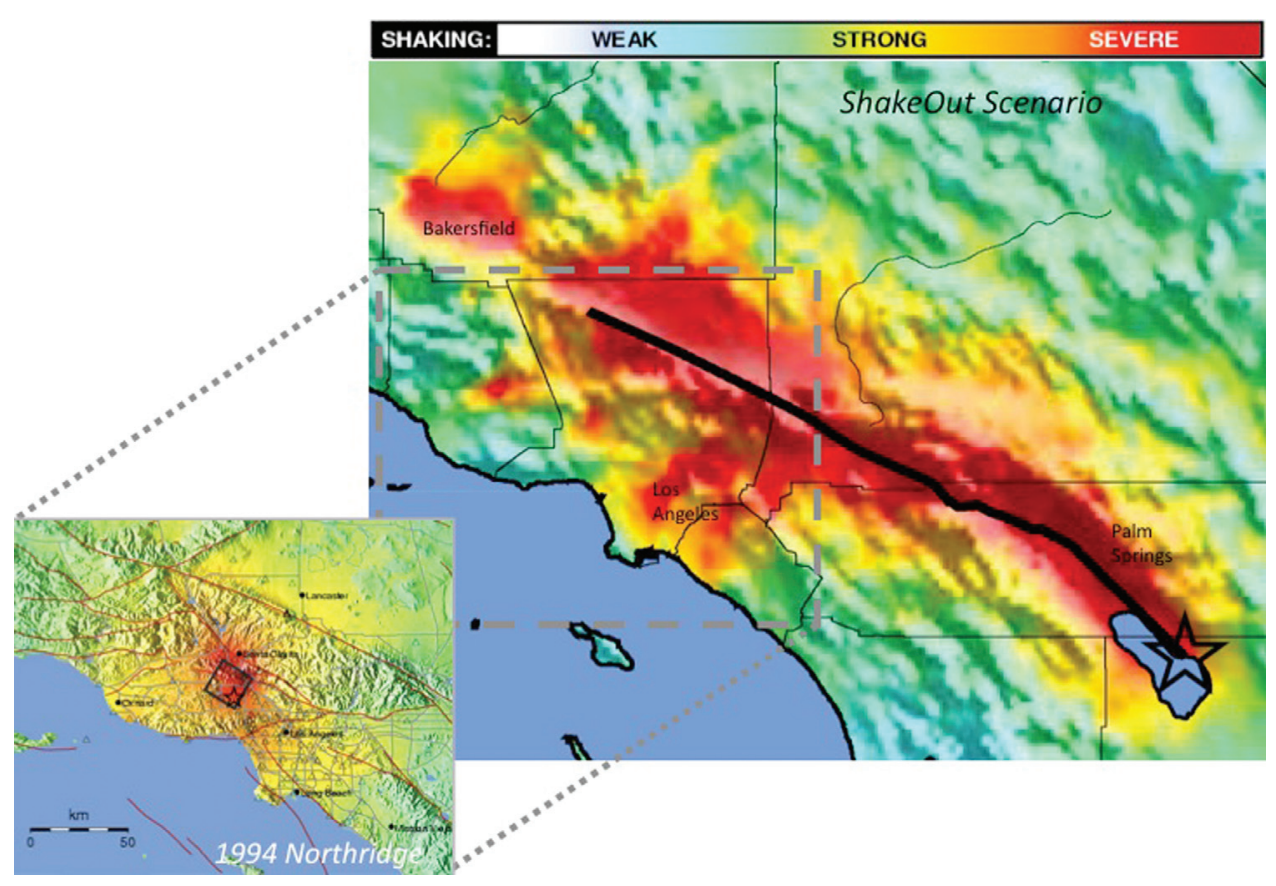

Figure 2. At the same scale, ShakeMaps for (a) the Northridge earthquake and (b) ShakeOut earthquake enabled viewers to comprehend the broader regional destruction to be anticipated in the larger event.

variation in shaking patterns, and resonance in sedimentary basins. The movie also helps people understand the potential value of earthquake early warning systems. This set of 16 animations was released just prior to the ShakeOut exercises. Having new visuals to show helped to re-engage the media and exercise participants who had seen the previous animation many times. As with the previous animation, these 16 movies were best understood by the general public when narrated by a speaker with an earth science background; we would add optional narration to downloadable versions for the next scenario.

The Scenario ShakeMap (USGS 2008) was created using the USGS ShakeMap capability to estimate intensity of ground shaking based on scenario ground motions. To simulate use during a real event, this scenario ShakeMap was made available through the CISN Display (http://www.cisn.org), an application installed on users' desktops to display recent earthquake information from the Advanced National Seismic System and the USGS. Professionals involved in emergency response, business continuity planning, and other occupations pertinent to risk management widely used the GIS version of the scenario ShakeMap to explore how the ShakeOut earthquake would affect their assets and areas of interest. Based on response at presentations, the ShakeMap was less meaningful to the lay public (an impression substantiated in a study by Bottomley 2008) except when shown at the same scale as the ShakeMap of the 1994, magnitude 6.7, Northridge earthquake (Figure 2). Juxtaposing the two ShakeMaps induced gasps from viewers and enabled many to grasp, for the 
first time, just how much bigger and more regionally damaging a magnitude 7.8 earthquake would be versus a magnitude 6.7 .

The scenario Open-File Report (Jones et al. 2008) was released for the use of Golden Guardian 2008 planners, but few of them even tried to read the 800+ pages of report, supplemental studies, and appendices. Instead, planners used the narrative to get a sense of the earthquake's likely impacts on their jurisdictions, used the ShakeMap and velocity animation to estimate shaking levels in their area, and used MHDP staff to distill essential information, which was provided in internal Golden Guardian planning documents. These distillations delivered the details most requested by Golden Guardian planners:

- Location-specific lifeline outages and restoration times

- $\quad$ Road damage and usability

- $\quad$ Damage to dams, airports, and ports

- Numbers and types of collapsed buildings

- Numbers of casualties within collapsed buildings

- Locations of train derailments

- Locations and details of hazmat incidents

- Locations of fires

- Locations, timing, and severity of large aftershocks

- Amount of debris created

- County- and city-specific details about casualties, debris, and damages.

Someone who knew where to look could extract some of these details from the published scenario. However, the planners often wanted more localized results than the regional study contained. In those cases, we reasonably extrapolated the regional results to more local situations.

To develop their exercises, the Golden Guardian planners recast scenario details into a Master Scenario Events List (MSEL), which is a chronological bullet list of information and actions that becomes the foundation for "injects," which are the blow-by-blow occurrences that drive an emergency response exercise. Each group that participated in Golden Guardian created its own MSEL to focus exercise play on the aspects of greatest concern to it, which might be communication in one group, and staff deployment in another. However, all the MSELs shared certain basic overlaps in scenario details. In future scenarios, MHDP will create a basic MSEL and scenario-related injects to help align scenario results with exercise development.

HAZUS tables and Office of Emergency Services (OES) maps. Numerous exercise planners requested that ShakeOut Scenario results be presented in tables that mimicked the format of HAZUS loss estimation reports; some exercise planners wanted results displayed on maps, as they would be mapped by the OES (now CalEMA) GIS department during an actual disaster response. These products were eventually produced, but only after the scenario OFR was released, causing logistical complications and some modest but noticeable discrepancies in results. In future scenarios, MHDP will anticipate the need for products in these familiar formats and provide them as part of the scenario release.

Customized presentations. Developers of the ShakeOut Scenario and organizers of the ShakeOut drills spent many months presenting the scenario to Golden Guardian planners, 
emergency responders, civil servants, government officials, corporations, community organizations, and members of the public. MHDP created variants of scenario slide sets to accommodate the distinct needs and concerns of different audiences and to keep scenario messaging consistent when relayed by numerous individuals. In addition, slide sets with copious notes were provided to lay persons acting as ShakeOut organizers in their communities. The creation of audience-specific slide sets has continued. When FEMA was developing a Catastrophic Plan (CatPlan) for Southern California based on the ShakeOut Scenario, MHDP provided customized documents that included some 20 distinct slide sets for expert groups developing the CatPlan.

\section{DISCUSSION AND CONCLUSIONS}

A scenario that is widely disseminated and correctly used can be a powerful aid in increasing community readiness for disasters. By these standards, the ShakeOut Scenario has achieved much success. We attribute this success to our scenario development criteria and to our focus on the creation of end user products.

Our scenario development criteria built on the experience of past scenario developers, and extended them in some key ways. Several of the ShakeOut Scenario's development criteria added additional stresses to the development process, but increased the value of the end result enough to make these worthwhile.

The inclusion of end users in the scenario development process provided numerous benefits, many of them unanticipated. The most important benefit may be the indication that many end user participants are not treating the scenario as a single preparedness event, but are continuing to apply it to make longer term changes in their organizations and lives. One of the most critical goals of the ShakeOut was to change the culture of preparedness in Southern California. Involving end users in scenario development so far seems to be contributing to that change, perhaps because the collaborative process has increased the sense of "ownership" of the earthquake problem.

There is no single publication or communication product that will meet all user needs, and we allocated significant resources to creation of customized, specialized documents and products for particular users. Scientific publication of the study has been essential to give the scenario credibility, and to support the careers of contributing scientists. However, we would have seen far narrower use of this scenario if we had followed the typical practice and handed off our completed scientific studies to end users, leaving them to find, interpret, and extract what they needed.

Our partnerships with visualization experts from the scientific and the design fields led to the creation of powerful, graphical and visual representations of scenario results and impacts. These products attracted widespread attention and promoted understanding. These products, as well as the evocative telling of the scenario as a narrative, confirm to us that it is possible to convey scientific results in ways that are accurate yet simple and compelling.

\section{REFERENCES}

Aagaard, B., 2008. Southern California ShakeOut Simulations, http://earthquake.usgs.gov/ regional/nca/simulations/shakeout/. 
Bottomley, H., 2008. Personal communication.

Cox, D. A., Jones, L. M., Ralph, F. M, Dettinger, M. D. Porter, K., Perry, S. C., Barnard, P. L., Hoover, D. Wills, C. J., Stock, J. D., Croyle, W., Ferris, J. C., Plumlee, G. S., Alpers, C. N., Miller, M., Wein, A., Rose, A., Done, J., Topping, K., 2009. ARkStorm: A West Coast Storm Scenario, Eos Trans. AGU 90, Fall Meet. Suppl., Abstract NH43A-1305.

Davis, J. F., Bennet, J. H., Borchardt, G. A., Kahle, J. E., Rice, S.J., and Silva, M. A., 1982. Earthquake planning scenario for a magnitude 8.3 earthquake on the San Andreas Fault in Southern California: The proposed effects of a repeat of the Great 1857 Fort Tejon earthquake on the Los Angeles, Ventura, and Orange Counties populations, California Geological Survey Special Publication 60.

Earthquake Engineering Research Institute (EERI), 2005. Scenario for a Magnitude 6.7 Earthquake on the Seattle Fault, Earthquake Engineering Research Institute, Oakland, CA.

Golden Guardian, 2008. Homeland Security Training and Exercises: Exercise Branch, http:// www.ohs.ca.gov/hseep/Exercise_Branch.html.

Goltz, J., and Mileti, D., 2011. Public response to a catastrophic Southern California earthquake: a sociological perspective, Earthquake Spectra 27, 487-504.

Graves, R., Aagard, B., Hudnut, K., 2011. The ShakeOut earthquake source and ground motion simulations, Earthquake Spectra 27, 273-291.

Jones, L. M., Bernknopf, R., Cox, D., Goltz, J., Hudnut, K., Mileti, D., Perry, S., Ponti, D., Porter, K., Reichle, M., Seligson, H., Shoaf, K., Treiman, J., and Wein, A., 2008. The ShakeOut Scenario: USGS Open File Report 2008-1150 and California Geological Survey Preliminary Report 25, http://pubs.usgs.gov/of2008/1150 and http://conservation.ca.gov/cgs, Sacramento, CA.

Jones, L. M., Bernknopf, R., Cannon, S., Cox, D., Gaydos, L., Keeley, J., Kohler, M., Lee, H., Ponti, D., Ross, S., Schwarzbach, S., Shulters, M., Ward, A. W., and Wein, A., 2007. Increasing Resiliency to Natural Hazards - A Strategic Plan for the Multi-Hazards Demonstration Project in Southern California, U.S. Geological Survey Open-File Report 20071255.

Porter, K., and Sherill, R., 2011. Utility performance panels in the ShakeOut Scenario, Earthquake Spectra 27, 443-458.

Perry, S., Cox, D., Jones, L., Bernknopf, R., Goltz, J., Hudnut, K., Mileti, D., Ponti, D., Porter, K., Reichle, M., Seligson, H., Shoaf, K., Treiman, J., and Wein, A., 2008. The ShakeOut Earthquake Scenario - A Story that Southern Californians Are Writing, U.S. Geological Survey Circular 1324 and California Geological Survey Special Report 207, 16 pp.

Preuss, J., and Godfrey, J., 2006. Guidelines for Developing an Earthquake Scenario. Earthquake Engineering Research Institute, Oakland, CA.

Steinbrugge, K.V., LaGorio, H. J., Davis, J. F., Bennett, J. H., Borchardt, G., and Toppozada, T. R., 1986. Earthquake planning scenario for a magnitude 7.5 earthquake on the Hayward fault, San Francisco Bay Area, California Geology 39.

U.S. Geological Survey (USGS), 2008. Scenario ShakeMap, http://earthquake.usgs.gov/earthquakes/ shakemap/list.php?s=1\&n=sc\&y\&=2008.

Wein, A., Johnson, L., and Bernkopf, R., 2011. Recovering from the ShakeOut earthquake, Earthquake Spectra 27, 521-538.

(Received 25 January 2010; accepted 14 May 2010) 